\title{
Hemophagocytic Lymphohistiocytosis: A Rare Disease Unveiling the Diagnosis of EBV-Related Large B Cell Lymphoma in a Patient with HIV
}

\author{
Alexandra Noveihed ( $\nabla$ anoveihed@gmail.com ) \\ Rutgers-Robert Wood Johnson Medical School \\ Shiochee Liang \\ Rutgers-Robert Wood Johnson Medical School \\ Joel Glotfelty \\ Rutgers-Robert Wood Johnson Medical School \\ Ibiyonu Lawrence \\ Rutgers-Robert Wood Johnson Medical School
}

\section{Case Report}

Keywords: Hemophagocytic lymphohistiocytosis, Epstein-barr virus associated B-cell lymphoma, acquired immunodeficiency syndrome

Posted Date: February 22nd, 2022

DOI: https://doi.org/10.21203/rs.3.rs-1374789/v1

License: (c) (i) This work is licensed under a Creative Commons Attribution 4.0 International License. Read Full License

Version of Record: A version of this preprint was published at Discover Oncology on March 21st, 2022. See the published version at https://doi.org/10.1007/s12672-022-00476-3. 


\section{Abstract}

Background: Hemophagocytic lymphohistiocytosis $(\mathrm{HLH})$ is a rare disease resulting from the overactivation of the immune system due to under regulation of cytotoxic lymphocytes, macrophages and natural killer (NK) cells. HLH is associated with malignancies, infections, autoimmune disorders and rarely AIDS and is rapidly fatal.

Case Presentation: This case report identified a 53 year old male with acquired immunodeficiency syndrome (AIDS) who presented with neutropenic fever of unknown origin. He had two previous hospitalizations prior to the hospitalization diagnosing $\mathrm{HLH}$. The first led to a diagnosis of drug fevers in the setting of treatment for thrombotic thrombocytopenic purpura and subsequent hospitalization led to empiric treatment of hospital acquired pneumonia after workup for intermittent fevers was negative. He was discharged but readmitted ten days after for recurrence of neutropenic fevers. During this final hospitalization, he was found to have elevated liver enzymes, ferritin, triglycerides and soluble IL-2 receptor with persistent fevers, new splenomegaly and bicytopenia meeting the $2004 \mathrm{HLH}$ criteria. Bone marrow biopsy confirmed the diagnosis of $\mathrm{HLH}$ as well as EBV associated large B-cell lymphoma. The patient improved on treatment with steroids, rituximab, tocilizumab, and chemotherapy but ultimately passed away due to refractory septic shock from multi-drug resistant Klebsiella pneumoniae.

Conclusion: This novel case highlights a patient diagnosed with $\mathrm{HLH}$ in the setting of several risk factors for the disease, including AIDS, B-cell lymphoma and EBV. Additionally, this case highlights the importance of early consideration of HLH in the setting of neutropenic fever without clear infectious etiology and search for malignancy associated reasons for HLH especially in immunocompromised patients.

\section{Background}

Hemophagocytic lymphohistiocytosis $(\mathrm{HLH})$ is an aggressive, rapidly fatal, and often misdiagnosed hyper-activation of the immune system that can be seen in a variety of malignancies, infections, autoimmune disorders, and rarely HIV'. This pathology results in excessive production of cytokines which in turn results in cellular destruction and eventual organ failure. We present the case of a 53-year-old male with HIV/AIDS who was admitted with neutropenic fever in the setting of bone marrow failure, which preceded a diagnosis of HLH from EBV related Large B Cell Lymphoma.

\section{Case Presentation}

A 53-year-old African-American male with a past medical history of HIV with CD 4 count of 27 and undetectable viral load, hypertension, hyperlipidemia, colitis status post hemicolectomy, polysubstance abuse who presented with fever of unknown origin. Notably, the patient has had two prior admissions three months before this presentation. On his first admission, he was diagnosed with Thrombotic Thrombocytopenic Purpura, responsive to caplacizumab and prednisone. His hospital course was 
complicated by intermittent persistent fevers, which was eventually attributed to drug fever. There was consideration of DRESS syndrome during this admission although the patient did not have eosinophilia, which one study suggests is present in $97 \%$ of patients with DRESS syndrome. Patient was discharged home but readmitted two weeks later with failure to thrive and was found to have neutropenic fevers of unknown origin. He underwent extensive workup for infectious etiology. CT chest showed persistent stable pulmonary nodules for which bronchoscopy was performed with lavage cytopathology significant only for colonized rare candida spp. He was found to have Epstein-Barr virus viremia. However, with no clear source he was treated empirically for hospital acquired pneumonia. He was discharged after resolution of his fevers to subacute rehab.

Ten days after discharge, he was readmitted for recurrence of neutropenic fevers, with absolute neutrophil count 532. Extensive workup revealed persistent fevers, splenomegaly, bicytopenia, elevated LFTs, ferritin, triglycerides, and soluble IL-2 receptor, meeting the 2004 hemophagocytic lymphohistiocytosis (HLH) criteria (Table 1-2). Lymph node biopsy confirmed the diagnosis of EBV associated lymphoma (Figure 2ad). Bone marrow biopsy confirmed the diagnosis of immunodeficiency associated large B-cell lymphoma with EBV associated HLH (Fig. 6-10). Patient was treated with a combination of steroids, rituximab, tocilizumab, and chemotherapy. Initially, the patient's status improved but unfortunately the patient ultimately expired 5 days after intensive care unit (ICU) downgrade due to refractory septic shock secondary to multidrug resistant Klebsiella pneumoniae.

\section{Discussion}

$\mathrm{HLH}$ is a rare disease associated with overactivation of the immune system, specifically the under regulation of cytotoxic lymphocytes, macrophages and natural killer (NK) cells. While primarily a pediatric entity, cases have been diagnosed in adults, with a predisposition for males and mean age range of 41-67 years, and an estimated incidence rate of 1 per 800,000 people' . Etiology is poorly defined but associated with genetic abnormalities specifically impairing perforins (a key delivery molecule for proapoptotic granzymes), especially in the pediatric population. $\mathrm{HLH}$ associated with genetic causes is termed primary $\mathrm{HLH}$. Our patient unfortunately cannot be excluded from the diagnosis of primary HLH as genetic causes were not tested during his admission. Nonetheless, our patient had multiple associations to make the likely diagnosis of secondary HLH.

In adults, a 2015 single center study found the etiology of secondary HLH was commonly due to infection (41.1\%), followed by malignancies (28.8\%). Of the infectious etiologies, HIV and EBV both were the most common causes $(5 / 30 \text { and } 5 / 30)^{2}$. Viral load of EBV quantified by PCR correlates with disease severity ${ }^{6}$. Interestingly, in our patient, his EBV viral load from previous admission was 38,000. As he further deteriorated and the diagnosis of HLH became clearer, his viral load increased to 97,900 (Table 1). Of the malignancy related causes, B-cell lymphoma was the most common, with 10 out of 21 patients $^{2}$. It is likely that the disease driving the patient's presentation was a combination of EBV, HIV and large B cell lymphoma. 
In our patient, the diagnosis of lymphoma was made on lymph node biopsy (Figure 1a-e) prior to the pathological diagnosis of HLH seen on bone marrow biopsy (Figure 2a-d). This diagnosis of lymphoma was EBV-related as evidenced by the positivity of EBER in-situ hybridization on lymph node and bone marrow biopsy. To our knowledge, there have been no retrospective or prospective studies defining the incidence of HLH with underlying HIV, EBV, and B cell lymphoma. We found one case report describing a similar patient presentation. Although NK function and genetics were not performed on our patient, our patient had clear triggers for HLH secondary to immune activation, rather than underlying genetic defects in lymphocytes, thus classifying his case under $\mathrm{HLH}$ disease rather than syndrome. Regardless, without treatment, HLH has a high mortality due to multiorgan failure.

According to the HLH-2004 trial, which determined the diagnostic criteria for $\mathrm{HLH}$, histological identification of HLH was not required to make a definitive diagnosis. Nonetheless, in patients with clinical suspicion for HLH, bone marrow biopsy to search for hemophagocytosis or underlying malignancy could help aid in the diagnosis. Further complicating the picture, the presence of hemophagocytosis in bone marrow biopsies was neither sensitive nor specific for the diagnosis of HLH. On the admission preceding the admission ultimately diagnosing $\mathrm{HLH}$, our patient had a bone marrow biopsy that was negative for hemophagocytosis. This leads us to question whether bone marrow biopsy should be performed on all patients suspected of $\mathrm{HLH}^{9}$. According to a retrospective analysis of $\mathrm{HLH}$ confirmed patients, bone marrow biopsy only showed hemophagocytosis in $70 \%$ of patients. In our case, bone marrow biopsy distinguished the underlying etiology of HLH (Figs. 2a-d). Our patient case highlights the importance of early consideration of $\mathrm{HLH}$ in the setting of neutropenic fever without clear infectious etiology. Additionally, this highlights the importance of identifying the etiology of secondary HLH, including malignancy. 
Table 1

Diagnostic evaluation of the patient based on $2004 \mathrm{HLH}$ criteria. The diagnosis of HLH Disease can be established by 5 of 8 criteria as fulfilled.

\begin{tabular}{|c|c|c|c|}
\hline HLH Criteria & $\begin{array}{l}\text { Admission preceding } \\
\text { the diagnosis of } \mathrm{HLH}\end{array}$ & $\begin{array}{l}\text { On diagnosis of } \\
\text { HLH }\end{array}$ & $\begin{array}{l}\text { After initiation of } \\
\text { HLH treatment }\end{array}$ \\
\hline Fever $>38.5 \mathrm{C}$ & Present & Present & Resolved \\
\hline Splenomegaly & Negative & Present (new) & $\begin{array}{l}\text { Decreased in size: } \\
12 \mathrm{~cm} \text { from } 14 \mathrm{~cm}\end{array}$ \\
\hline \multirow{2}{*}{$\begin{array}{l}\text { Cytopenias (affecting at least } 2 \text { of } \\
3 \text { lineages in the peripheral blood) }\end{array}$} & ANC: $0.4-1.4$ & ANC: 0.5 & ANC: 1.90 \\
\hline & $\mathrm{Hg}: 7.3-8.9$ & $\mathrm{Hg} 7.4$ & Hg: 9.4 \\
\hline Platelets $<100 \times 10^{3} / \mathrm{mL}$ & \multirow[t]{2}{*}{ Platelets: $108-220$} & \multirow[t]{2}{*}{ Platelets 88} & \multirow[t]{2}{*}{ Platelets 52} \\
\hline Neutrophils $<1 \times 10^{3} / \mathrm{mL}$ & & & \\
\hline Hypertriglyceridemia & N/A & TGs 469 & TGs 191 \\
\hline (fasting $>265 \mathrm{mg} / \mathrm{dL}$ ) & \multirow[t]{4}{*}{ Fibrinogen: 729-864 } & \multirow[t]{4}{*}{$\begin{array}{l}\text { Fibrinogen: } \\
\text { 197-661 }\end{array}$} & \\
\hline$+/-$ & & & \\
\hline Hypofibrinogenemia & & & \\
\hline$(<150 \mathrm{mg} / \mathrm{dL})$ & & & \\
\hline $\begin{array}{l}\text { Hemophagocytosis in bone } \\
\text { marrow, spleen, lymph nodes, or } \\
\text { liver }\end{array}$ & $\begin{array}{l}\text { Negative on bone } \\
\text { marrow biopsy }\end{array}$ & $\begin{array}{l}\text { Positive on } \\
\text { bone marrow } \\
\text { biopsy }\end{array}$ & N/A \\
\hline Low or absent NK cell activity & N/A & N/A & N/A \\
\hline \multirow[t]{2}{*}{ Ferritin $>500 \mathrm{ng} / \mathrm{mL}$} & \multirow[t]{2}{*}{$\mathrm{N} / \mathrm{A}$} & $\begin{array}{l}6751 \text { (on } \\
\text { admission) }\end{array}$ & \multirow[t]{2}{*}{6226} \\
\hline & & 52823 (peak) & \\
\hline $\begin{array}{l}\text { Elevated sCD } 25 \text { (soluble IL-2 } \\
\text { Receptor) }\end{array}$ & $\mathrm{N} / \mathrm{A}$ & $\begin{array}{l}5657 \mathrm{U} / \mathrm{mL} \\
\text { (High) }\end{array}$ & N/A \\
\hline CXCL9 (not part of 2004 criteria) & $\mathrm{N} / \mathrm{A}$ & $\begin{array}{l}44,417 \mathrm{pg} / \mathrm{mL} \\
\text { (High) }\end{array}$ & $\mathrm{N} / \mathrm{A}$ \\
\hline
\end{tabular}


Table 2

Other important biomarkers not included in $2004 \mathrm{HLH}$ criteria but assisting in the diagnosis of $\mathrm{HLH}$.

\begin{tabular}{|lll|}
\hline Notable Labs & Admission preceding the HLH diagnosis & Admission with diagnosis of HLH \\
\hline EBV Viral Titer & 38,000 & 97,900 \\
\hline LDH & $225-401$ & $326-3914$ \\
\hline ALT /AST & $30 / 14$ & $34 / 135$ \\
\hline Total Bilirubin & 0.2 & 5.6 \\
\hline Direct Bilirubin & $<0.2$ & 4.2 \\
\hline ALP & 213 & 447 \\
\hline
\end{tabular}

\section{Abbreviations}

$\mathrm{HLH}$

hemophagocytic lymphohistiocytosis

EBV

ebstein-barr virus

HIV

human immunodeficiency virus

AIDS

acquired immunodeficiency syndrome

\section{Declarations}

\section{Consent}

Informed consent was obtained from the family of the patient in this case report. A copy of the written consent is available for review by the authors of this case report.

\section{Competing interests}

The authors declare that they have no competing interests.

\section{Funding}

There was no funding for this manuscript.

\section{Data Availability}

Data availability is not applicable to this article as no datasets were generated or analyzed during this case report. 


\section{Authors' contributions}

SL and AN assembled, analyzed and interpreted the patient data regarding the hematological disease. All authors contributed to writing the manuscript. All authors read and approved the final manuscript.

\section{Acknowledgements}

Thank you to Payal Sojitra, MD and Virian D. Serei, MD, PhD for providing the histological images and captions in this case report.

\section{References}

1. Asanad S, Cerk B, Ramirez V. Hemophagocytic lymphohistiocytosis (HLH) secondary to disseminated histoplasmosis in the setting of Acquired Immunodeficiency Syndrome (AIDS). Med Mycol Case Rep. 2018;20:15-17. Published 2018 Jan 10. doi:10.1016/j.mmcr.2018.01.001

2. Otrock ZK, Eby CS. Clinical characteristics, prognostic factors, and outcomes of adult patients with hemophagocytic lymphohistiocytosis. American journal of hematology. 2015;90(3):220-224. doi:10.1002/ajh.23911

3. Emiloju OE, Gupta S, Arguello-Guerra V, Dourado C. Hemophagocytic Lymphohistiocytosis in an AIDS Patient with Kaposi Sarcoma: A Treatment Dilemma. Case Rep Hematol. 2019;2019:7634760. Published 2019 Oct 7. doi:10.1155/2019/7634760

4. Skowron F, Bensaid B, Balme B, et al. Drug reaction with eosinophilia and systemic symptoms (DRESS): clinicopathological study of 45 cases. J Eur Acad Dermatol Venereol. 2015;29(11):21992205. doi:10.1111/jdv.13212

5. Jordan MB, Allen CE, Weitzman S, Filipovich AH, McClain KL. How I treat hemophagocytic lymphohistiocytosis. Blood. 2011;118(15):4041-4052. doi:10.1182/blood-2011-03278127

6. Kim WY, Montes-Mojarro IA, Fend F, Quintanilla-Martinez L. Epstein-barr virus-associated T and NKcell lymphoproliferative diseases. Frontiers in pediatrics. 2019;7:71-71. doi:10.3389/fped.2019.00071

7. Ramos-Casals M, Brito-Zerón P, López-Guillermo A, Khamashta MA, Bosch X. Adult haemophagocytic syndrome. The Lancet (British edition). 2014;383(9927):1503-1516. doi:10.1016/S0140-6736(13)61048-X

8. Stepp SE, Dufourcq-Lagelouse R, Le Deist F, et al. Perforin gene defects in familial hemophagocytic lymphohistiocytosis. Science. 1999;286(5446):1957-1959. doi:10.1126/science.286.5446.1957.

9. Lin, N., J. A. Hippensteel, and A. Neumeier. "Secondary Hemophagocytic Lymphohistiocytosis in AIDS Associated EBV+ Diffuse Large B-Cell Lymphoma." B46. CRITICAL CARE CASE REPORTS: 
HEMATOLOGY, ONCOLOGY, RHEUMATOLOGY, AND IMMUNOLOGY. American Thoracic Society, 2018. A3392-A3392.

10. Gars E, Purington N, Scott G, et al. Bone marrow histomorphological criteria can accurately diagnose hemophagocytic lymphohistiocytosis. Haematologica. 2018;103(10):1635-1641. doi:10.3324/haematol.2017.186627

11. Rivière $S$, Galicier $L$, Coppo $P$, et al. Reactive hemophagocytic syndrome in adults: a retrospective analysis of 162 patients. Am J Med. 2014;127(11):1118-1125. doi:10.1016/j.amjmed.2014.04.034

\section{Fig. 6-10}

Fig. 6-10 are not available with this version.

\section{Figures}
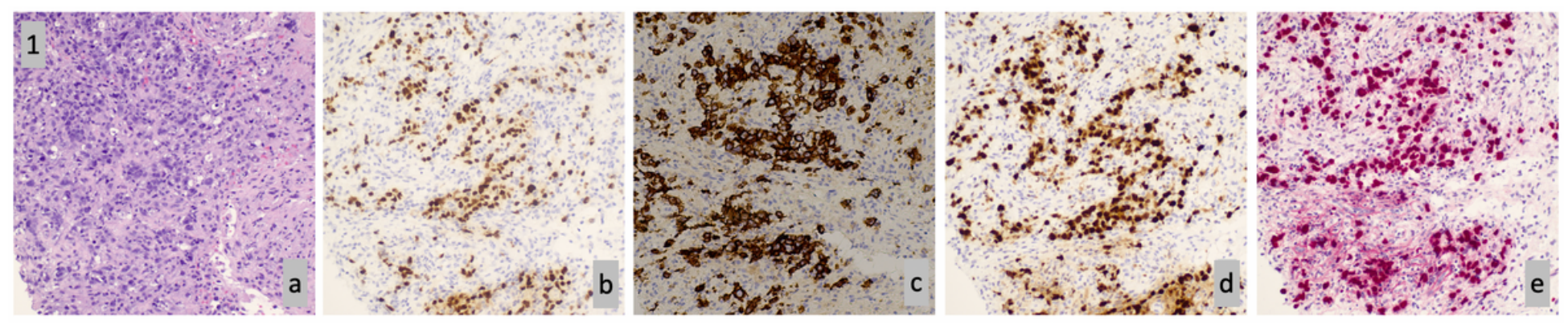

\section{Figure 1}

Retroperitoneal Lymph Node Biopsy. H\&E stained core biopsy of the retroperitoneal lymph node shows sheets and clusters of large, pleomorphic cells, with some showing prominent nucleoli. Numerous mitoses are observed. (Figure 1a, H\&E). By immunostain, the cells are positive for Pax-5 (Figure 1b), CD30 (Figure 1c), and MUM-1 (Figure 1d). EBER in-situ hybridization is positive (Figure 1e). 


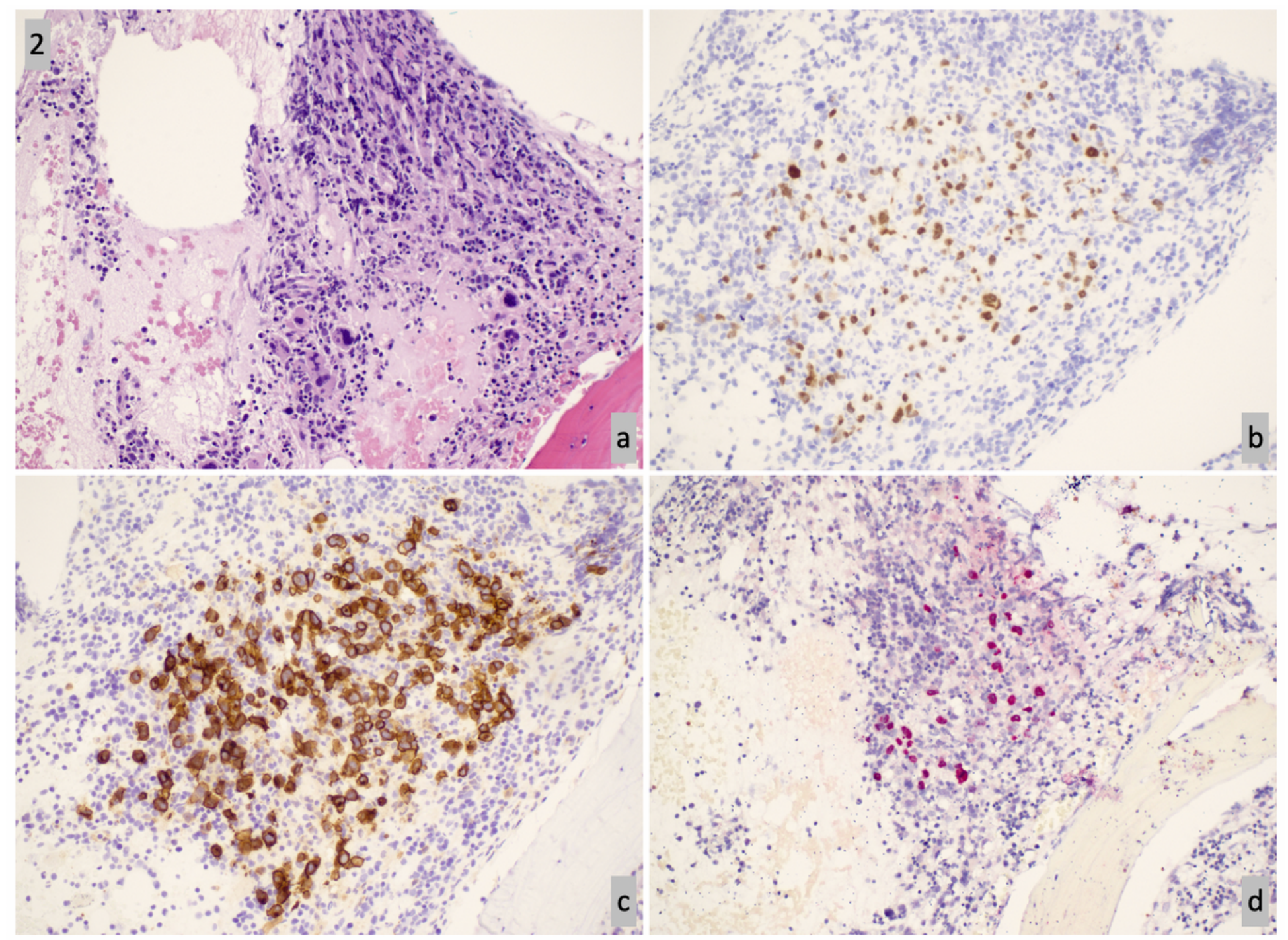

\section{Figure 2}

Bone Marrow Biopsy. H\&E stained bone marrow core biopsy shows a hypercellular bone marrow for age with clusters of large abnormal lymphoid cells (Figure 2a) that are positive for Pax-5 (Figure 2b) and CD30 (Figure 2c) by immunostain, and positive for EBER by in-situ hybridization (Figure 2d). 


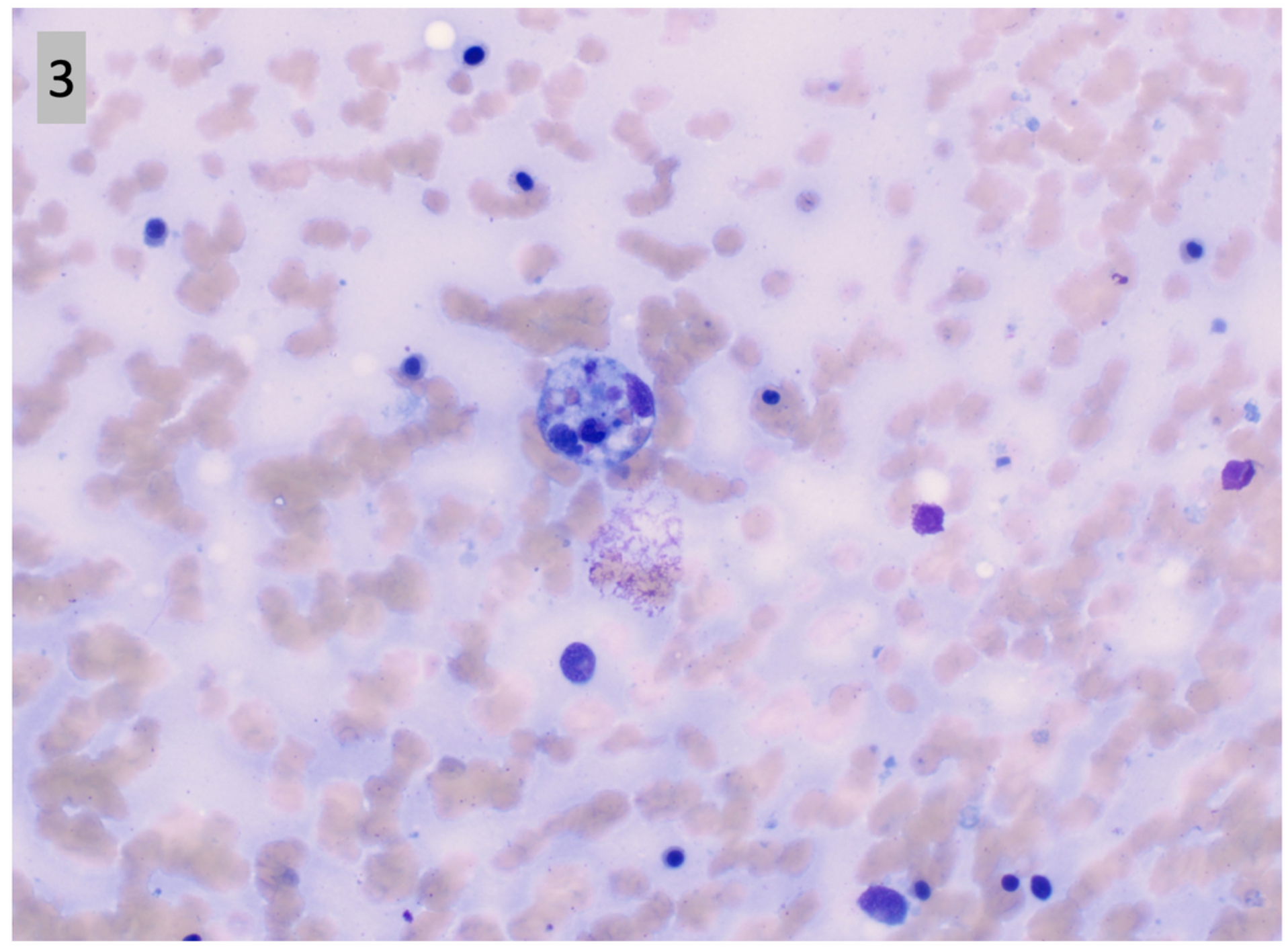

\section{Figure 3}

A representative hemophagocytic histocyte is pictured from a Wright-Giemsa stained bone marrow aspirate smear. 